\title{
Morphology and Performance Characterizations of 316 Stainless Steel Additively Fabricated by Laser Thermal-Joule Heating Composite Process
}

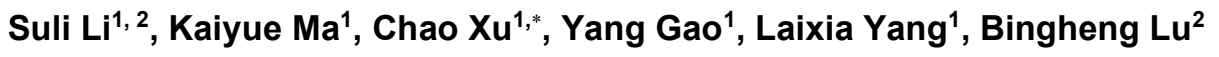 \\ 1. School of Mechanical Engineering, Xi'an University of Science and Technology, Xi' an 710054, China \\ 2. State Key Laboratory for Manufacturing Systems Engineering, Xi'an Jiao tong University, Xi'an 710049, China; \\ *Correspondence: Chaoxu@xust.edu.cn
}

\begin{abstract}
The Laser Thermal-Joule Heating Composite Process was studied by orthogonal tests based on an analysis of fabrication parameters such as the laser power, wire feeding speed, and electric current. Temperature profiles and the geometric morphology of deposited layers under different process parameters were analyzed, and the overlaps between the layers and the substrate were observed. Results show that when the temperature at the bottom layer of the additive manufacturing is higher than the melting point of the substrate, and the highest temperature at the top layer does not exceed the over-firing temperature, good morphology and close bonding with the substrate can be obtained. Finally, appropriate process parameters were identified and verified to print multiple layers continuously.
\end{abstract}

Keywords: Laser power; Joule heat; Composite heat source; Temperature field; Additive manufacturing

\section{Introduction}

Additive manufacturing (AM) has seen increased popularity in manufacturing for direct fabrication. AM technologies for metal products can be classified as powder- or wire-fed based on the form of feedstock unit [1]. To meet the growth demands for laser cladding application in industry, both the material utilization rate as well as the deposition efficiency must be increased [2]. Currently, the material utilization rate is close to $100 \%$ for wire fillers while only $40-60 \mathrm{wt} \%$ for powders [3]. The deposition rate of laser cladding is directly related to the energy input. High-energy input, (i.e. high laser power), allows more materials to be deposited, though not necessarily with high quality [4].

Recently, a hybrid deposition process named Laser Thermal-Joule Heating Composite Additive Manufacturing (LT-JH CAM) has been developed in order to enhance the deposition rate as well as to increase the material utilization rate [5]. During the deposition process, an additional power supply was applied between the substrate and the wire. The resistant heat by preheating the wire will increase the wire feed rate, and consequently increase the deposition rate [6]. Parts made by the LT-JH CAM method are very likely to fit the requirements of users in terms of efficiency and quality [7]. Wen Peng et al. [8-10] conducted an experimental study on the welding seam formation of LT-JH 
CAM process parameters. The results show that the current was appropriate to produce the welding wire melt in the molten pool, the weld seam was compact and the surface accuracy is good. Dieter Tyralla et al. [11] applied different types of wires such as Inconel 625, Stellite 21 and 2209 stainless steel made by the LT-JH CAM process to enhance service performance of the hydraulic piston rods against corrosion and wear. The Stellite 21 and Inconel 625 were found to obtain the highest localized corrosion resistance. The Stellite 21 showed the highest resistance to the scratch test. The authors [12-15] pointed out that the applied energy should be as high as possible to preheat the wire close to its melting point with-out generating arc and optimized the processing parameter of the LT-JH CAM process through the response surface method (RSM). By applying their optimized parameters, a coating with low surface roughness, low dilution, and no inter-track porosity was obtained.

According to the reviewed literature, it is inferred that there must be an optimal resistance heat in LT-JH CAM process, which can make full use of resistance heat and reduce the dependence on laser without causing the welding wire to fuse outside the molten pool. So, at present, most experts and scholars study the relationship between additive manufacturing process and forming quality, such as laser power, wire feeding speed, feed speed and so on. However, this article mainly starts from the perspective of environmental protection and studies the relationship between laser power and electric power (this article mainly studies the current) under the premise of ensuring the quality of parts.

In this study, LT-JH CAM of 316 stainless steel wire was investigated. First, Introduction of experimental methods and materials. Second, the effects of laser power, scanning speed, substrate temperature, current, wire feeding speed, and voltage on the single-layer fabricated coatings were investigated, which mainly adjusts the laser power and current value, simultaneously a $C C D$ was adopted to monitor the temperature at different locations of the single-layer fabricated coatings in LT-JH CAM process. Third, based on the optimization of the process parameters of single-layer fabricated coatings, multi-track coatings were manufactured under different laser power and current values. Last, the density, tensile performance and industrial CT test of the fabricated coatings were investigated.

\section{Fabrication Methods}

\subsection{Alloy Composition and Material}

The 316 stainless steel of wire and substrate are used in this study and chemical composition is given in table 1 as follows [16].

Table 1. Chemical composition of the 316 stainless steel of wire and substrate

\begin{tabular}{|c|c|c|c|c|c|c|c|c|}
\hline 316 stainless steel & $\mathrm{C}$ & $\overline{\mathrm{Si}}$ & $\mathrm{Mr}$ & $P$ & $\bar{S}$ & $\overline{\mathrm{Ni}}$ & $\mathrm{Cr}$ & $\overline{\mathrm{Mo}}$ \\
\hline $\mathrm{Wt} \%$ & $\leq 0.08 \%$ & $\leq 1 \%$ & $\leq 2 \%$ & $\leq 0.045 \%$ & $\leq 0.03 \%$ & $10.0 \% \sim 14.0 \%$ & $16.0 \% \sim 18.0 \%$ & $2.00 \%-3.00 \%$ \\
\hline
\end{tabular}

\subsection{Forming principle and experimental device}

The principle of this study is to use a pulsating wire feeding mechanism and a programmable heating power supply to short-circuit the metal wire and the substrate. The wire is melted by resistance heating, coordinated with the pulsating behavior and output current during the feeding process of the wire, to achieve quantitative melting of the ends of the wire, and to realize the additive manufacturing of parts during the laser-assisted heating process. The highspeed camera system $C C D$ can monitor the wire heating process, which is shown as Figure 1. Compared with the 
existing mainstream high-energy beam additive manufacturing technology, the method in this study has the following advantages of low equipment cost, high-energy conversion efficiency, high forming efficiency, and small deformation. In addition, it can solve the problems of large stress, large deformation and easy cracking of many parts, which has great research value and application prospects.

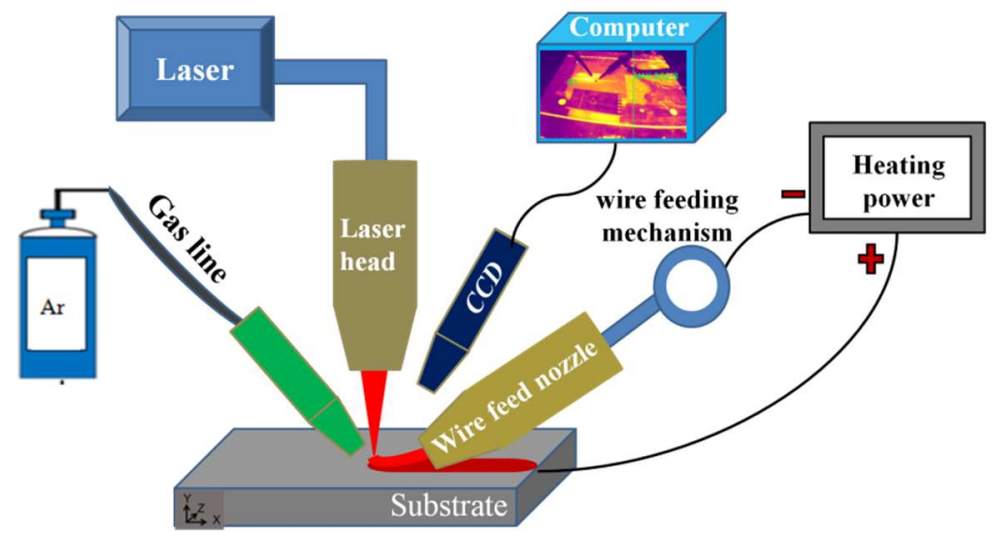

Figure 1. Composite additive manufacturing

Figure 2 shows the experimental system and they mainly consist of a wire feeder (Shanghai, China), gas line (Pure argon, 99.999\%), laser head (RUIKE Wuhan, China), heating equipment (the substrate is connected to the negative pole of the power, and the wire is connected to the positive pole of the power) and 316 stainless steel substrate (CHALCO, Chongqing, China). The resistance heating power supply used in this research is a $10 \mathrm{~V}-150 \mathrm{~A}$ DC switching power (KESHIYUAN, Guangdong, China). Among them, Wire feeder is used to control the speed of wire feeding, the heating equipment is used to heat the wire, and there is another heating device under the substrate to preheat the substrate.

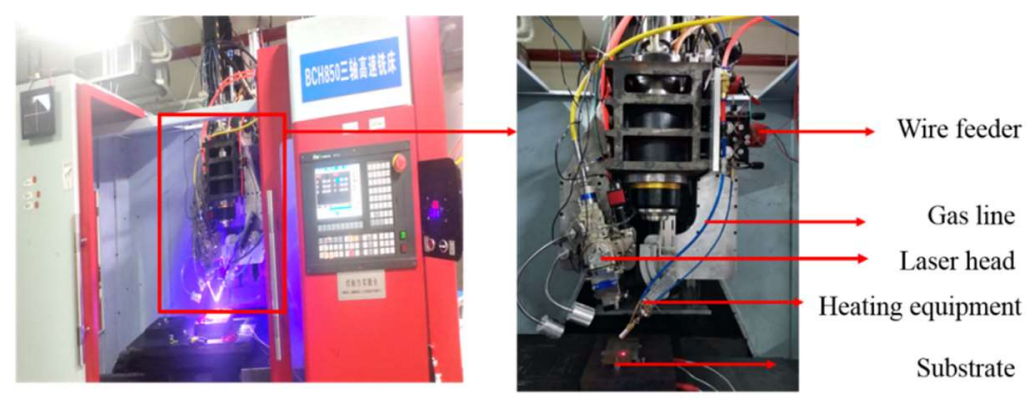

Figure.2. Schematic diagram of experimental system

\subsection{Temperature field simulation model}

LT-JH CAM is a complex physicochemical metallurgical process accompanied by acousto-optic multiparameter interaction coupling. The temperature signal of the molten pool is an important factor affecting the quality, because it can reflect the heat flow, mass transfer, energy distribution, etc. during the cladding process, and it directly determines the size, morphology and microstructure of the cladding layers. Affect the overall performance and surface quality of the cladding layer. At present, in the detection of the temperature of the laser molten pool, non-contact radiation temperature measurement is the most commonly used, including monochromatic temperature measurement, colorimetric temperature measurement, and $C C D$ image signal acquisition temperature measurement. However, 
because the molten pool is in a dynamic process, these detection methods currently have certain errors. Therefore, this study uses a combination of numerical simulation and experimental verification to achieve quantitative control of the molten pool temperature through temperature monitoring, thereby effectively improving the quality of the cladding.

\subsubsection{The heat source model}

According to the current proposed volumetric heat source, the double ellipsoid heat source can well describe the shape of the molten pool when the heat source moves in the depth direction, the similar semi-ellipsoidal heat source is used in this study. The difference between them is that due to the influence of the movement of the heat source, the heating area at the front of the heat source is smaller than that at the back. Therefore, the semi-axial length of the front hemisphere of the double ellipsoid is smaller than the semi-axial length of the rear hemisphere, while for the semiellipsoid heat source In other words, the front and rear hemispheres are completely similar. In this experiment, the moving speed of the platform is only $0.005 \mathrm{~m} / \mathrm{s}$. When the heat source moves, the front and back heating areas of the heat source have little effect. Therefore, this article believes that the semi-ellipsoidal heat source can be used to replace the actual heat source[17].

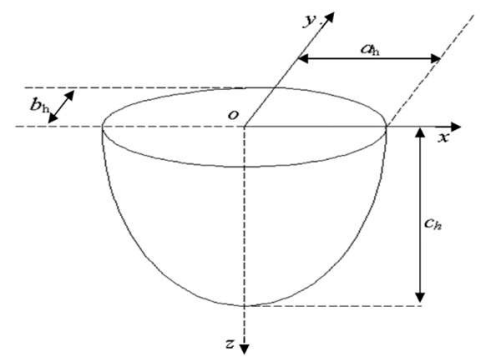

Figure 3 Schematic diagram of distribution area of semi-ellipsoid

As shown in Figure 3, suppose the semi-axes of the ellipse are $a_{h}, b_{h}, c_{h}$, at the center of the heat source, that is, the origin of the coordinate system $(0,0,0)$, the maximum heat flux density is $q_{m}$, and the function expression of the heat flux distribution is:

$$
q(x, y, z)=q_{m} * \exp \left(-A x^{2}-B y^{2}-C z^{2}\right)
$$

In the formula, $A, B, C$ are the heat flow volume distribution parameters. Through a series of derivations, we can get:

$$
q(x, y, z)=\frac{6 \sqrt{3} Q}{a_{h} b_{h} c_{h} \pi^{1.5}} \exp \left(\frac{-3 x^{2}}{a_{h}^{2}}+\frac{-3 y^{2}}{b_{h}^{2}}+\frac{-3 z^{2}}{c_{h}^{2}}\right)
$$

The parameters $a_{h}, b_{h}$ and $c_{h}$ should be selected reasonably according to the actual measured penetration depth and penetration width of the bonding zone of the cladding layer.

\subsubsection{Substrate heating heat source model}

During the experiment, it is necessary to preheat the bottom plate in advance. The purpose of this is to reduce the temperature gradient during the printing process, so that the quality of the cladding molding can be guaranteed. Because the bottom plate has been heated for a period of time at the beginning of the experiment, the substrate can be regarded as a constant temperature value during the numerical simulation. The treatment of this heat source is to load the bottom surface of the substrate with a constant temperature as a load. 


\subsubsection{Loading model}

First the model into the transient temperature analysis module is imported, then the grids are divided, Enter the temperature of the environment, set the convection heat transfer method, and load it in the heat flux method. When the wire feeder sends the wire to contact with the substrate, the heat source is loaded on the head of the wire and moves over time, dividing the loading process into several loading steps. According to "time step = unit size/scanning speed", when the unit size is unchanged and the time step is increased, the scanning speed becomes slower. For example, according to the actual laser power is $600 \mathrm{w}$, the light source radius is $0.001 \mathrm{~m}$, the platform moving speed is $0.005 \mathrm{~m} / \mathrm{s}$, the effective thermal power value and formula (3) can determine the heat flux expression as:

$$
q(r)=\frac{3 * 600 * 0.5}{\pi * 0.001^{2}} * e^{\left(-\frac{r^{2}}{0.005^{2}}\right)} \rightarrow q(x, y, t)=2.9 \times 10^{8} * e^{\left(-3 *\left(\frac{(x-0.01-0.005 t)^{2}+y^{2}}{0.001^{2}}\right)\right)}
$$

Its meaning is to load a heat source with a maximum heat flux density of $2.9 \times 10^{8} \mathrm{~W} / \mathrm{m}^{2}$ Gaussian distribution at the center of the heat source. The starting point of the heat source is the position of $x=0.01$, and it moves in the positive direction of the $\mathrm{X}$-axis at a speed of $0.005 \mathrm{~m} / \mathrm{s}$.

According to the use of electric heating current $32 \mathrm{~A}$, voltage $5 \mathrm{~V}$ and formula (2), the heat flux expression can be determined as:

$$
q_{2}(x, y, z, t)=\frac{6 \sqrt{3} * 32 * 5 * 0.7}{0.0015 * 0.001^{2} * \pi^{1.5}} \exp \left(\frac{-3(x-0.01-0.005 t)^{2}}{0.001^{2}}+\frac{-3 y^{2}}{0.001^{2}}+\frac{-3 z^{2}}{0.0015^{2}}\right)
$$

Its meaning is to load a heat source with a maximum heat flux density of $1.6 \times 10^{11} \mathrm{~W} / \mathrm{m}^{2}$ semi-ellipsoid in the center of the heat source. The starting point of the heat source is the position of $x=0.01$, and it moves in the positive direction of the $\mathrm{x}$-axis at a speed of $0.005 \mathrm{~m} / \mathrm{s}$.

\subsubsection{Temperature field simulation model}

In this study, the finite element software is used for analysis and hexahedral cells are used for meshing. Because the physical properties of the cladding layer and the substrate are different, the grid division of the cladding layer is refined, and a coarse grid is used at a position far from the scanning area to increase the calculation speed. Use formula (1-4) to import the interface for definition to complete the loading of dual heat sources. At the same time, apply a constant temperature load to the lower surface of the substrate, and then observe the time for heat transfer to the upper surface of the substrate. Wait for this period of time before applying dual heat sources to simulate the temperature of the preheating process of the substrate [18].

The laser and electric composite additive manufacturing equipment is used. And the laser is irradiated on the substrate to form a molten pool. When the current passes through the wire and the substrate contact resistance, a huge amount of heat is generated. At the same time, under the control of the computer, the laser and the wire feeding head move to the preset direction. The mechanism feeds the wire at a certain speed so that it can quickly contact the substrate after melting and breaking. As the liquid metal solidifies again, an additive manufacturing layer is formed. Temperature probe monitoring points $A, B, C$ and $D$ were selected and temperature-time change images of different process parameters, as shown figure 4 . 


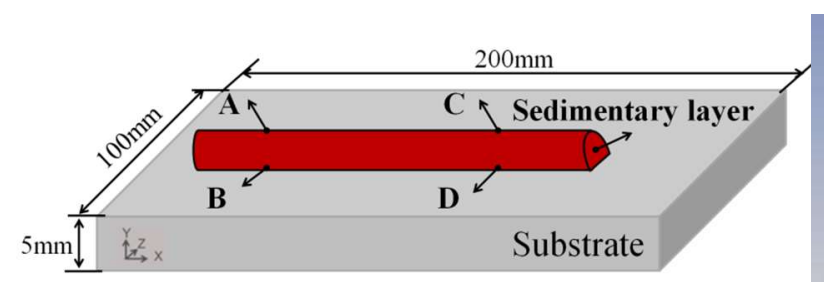

(a)

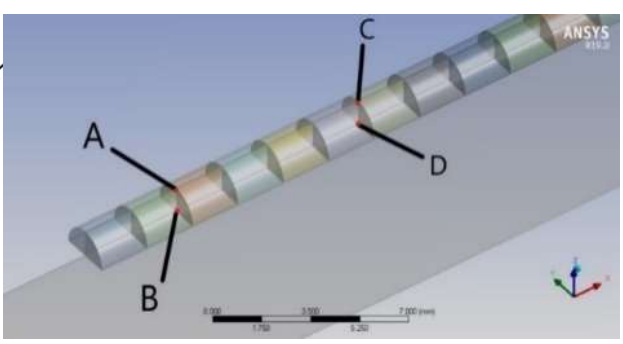

(b)

Figure 4. (a) Schematic graph of the temperature probe monitoring points; (b) the dimensions of sample.

\subsection{Experimental methods}

In this study, the numerical analysis parameters, include the length of the layer $(58 \mathrm{~mm})$, the scanning speed $(5 \mathrm{~mm} / \mathrm{s})$, the voltage $(10 \mathrm{~V})$, the laser power $(250 \mathrm{~W}, 200 \mathrm{~W}$ and $150 \mathrm{~W}$ respectively) and the current value (4A, $16 \mathrm{~A}$, $25 \mathrm{~A}$ and $32 \mathrm{~A}$ respectively). The parameters are shown in Table 2.This article focuses on the characteristics of forming parts under different laser powers and currents.

Table 2. Deposition parameters

\begin{tabular}{cc}
\hline Parameters & Numerical value \\
\hline Laser power $/ W$ & $250,200,150$ \\
Current $/ A$ & $4,16,25,32$ \\
Voltage $/ V$ & 10 \\
Substrate temperature $/{ }^{\circ} \mathrm{C}$ & 250 \\
Wire feeding speed $/ \mathrm{mm}^{\mathrm{min}}{ }^{-1}$ & 540 \\
Scanning speed $/ \mathrm{mm}^{-1}$ & 5 \\
\hline
\end{tabular}

After deposition, the as-deposited blocks were characterized to examine the morphology and the density. Specimens for tensile testing and industrial CT test were machined along horizontal and vertical directions from the as-deposited walls by wire electrode cutting. Sampling positions are shown schematically in Figure 5a. Before that, 3 $\mathrm{mm}$ of both ends of each wall were cut off and discarded and then machined as shown in Figure $5 \mathrm{~b}$. The measured density of the sample used the AG204 electronic balance (Mettle Toledo, Switzerland) with a measurement accuracy of $0.1 \mathrm{mg}$ and a maximum range of $210 \mathrm{~g}$. Tensile samples were machined in accordance with ISO 6892-1-2009 standard. Tensile tests were performed at room temperature on an electro-mechanical universal testing machine (Instron, Norwood, MA, USA) with a constant quasi-static velocity of $1 \mathrm{~mm} / \mathrm{min}$. Industry CT with a Buehler Omni Met image analysis system was employed to reveal the micro defect of the samples. 


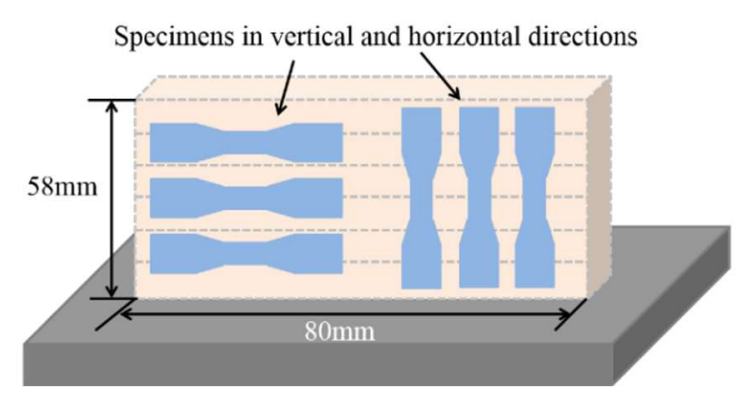

(a)

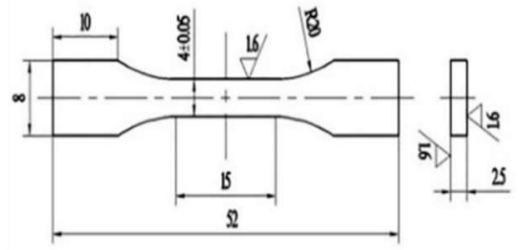

(b)

Figure5 (a) Schematic graph of the sampling positions; (b) the dimensions of tensile sample.

\section{Results and Discussion}

\subsection{Temperature field analysis and morphology characterization}

\subsubsection{Temperature field analysis}

The laser power is $250 \mathrm{w}$, and it is found that under the process parameters shown in Figure 6(a), the maximum temperature of point $\mathrm{A}, \mathrm{C}$, and $\mathrm{D}$ exceeds $1200^{\circ} \mathrm{C}$, but the maximum temperature of point $\mathrm{B}$ is lower than $1200^{\circ} \mathrm{C}$. It shows that although the wire is melted at this time, the transition zone of the additive manufacturing layer and the substrate may not be sufficiently dense, which is the "critical point" to be found. When the current is increased, the parameters at each point can meet our requirements. If the maximum temperature is too high when the current is increasing to $16 \mathrm{~A}$ or $25 \mathrm{~A}$, the over burning will occur, so the process parameters shown in (b) are reasonable.

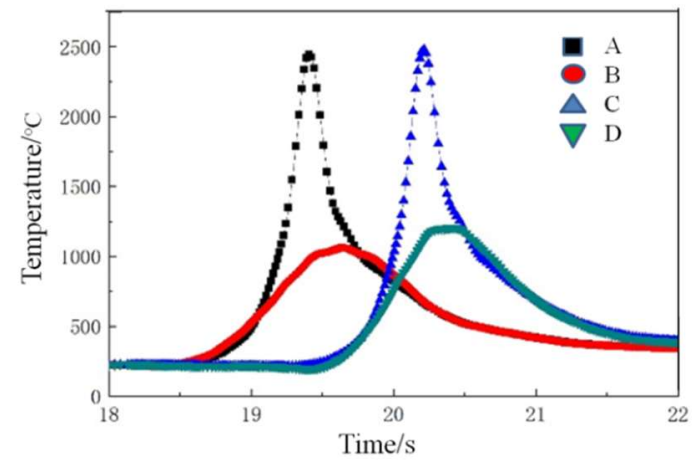

(a)

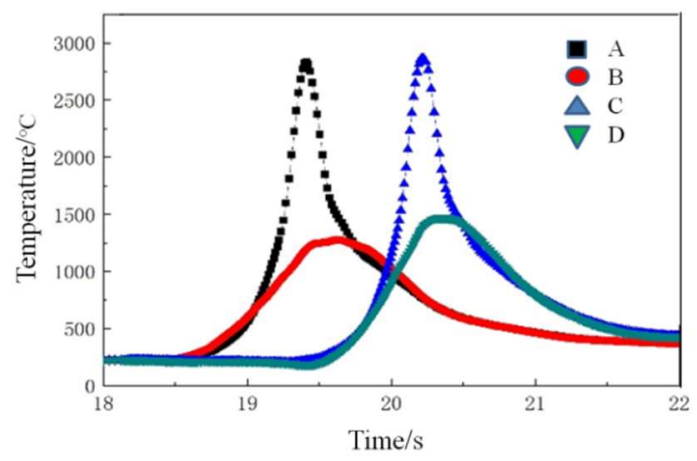

(c)

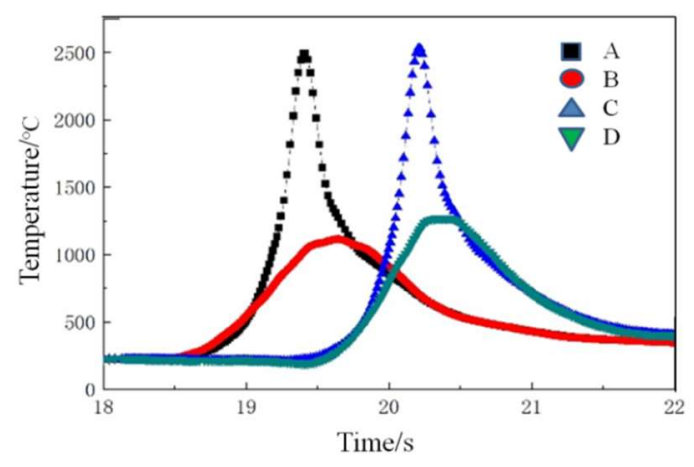

(b)

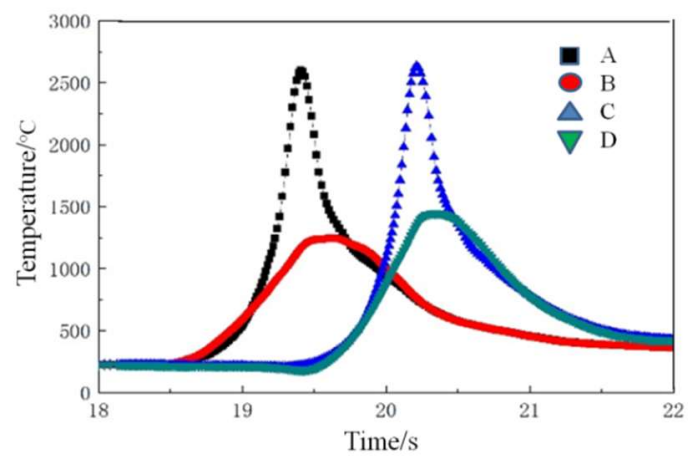

(d)

Figure 6 Temperature-time curve with laser 250w different current (a) 4A; b) 16A ;(c) 25A; (d) 32A 
When the laser power is $200 \mathrm{w}$ and the current is 4, 16, 25 and 32 A respectively, the maximum temperature of point B does not reach the melting point of the metal, which cannot be well combined with the substrate in Figure6a while the maximum temperature of point $\mathrm{B}$ has reached the melting point of the metal, which can be well combined with the substrate in Figure6b, Figure6c and Figure7d.

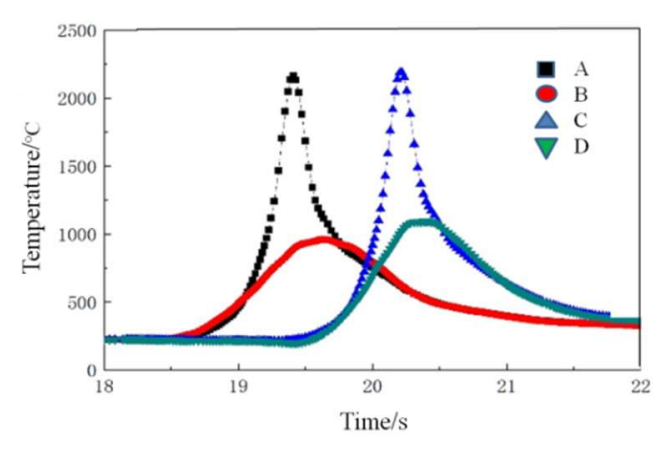

(a)

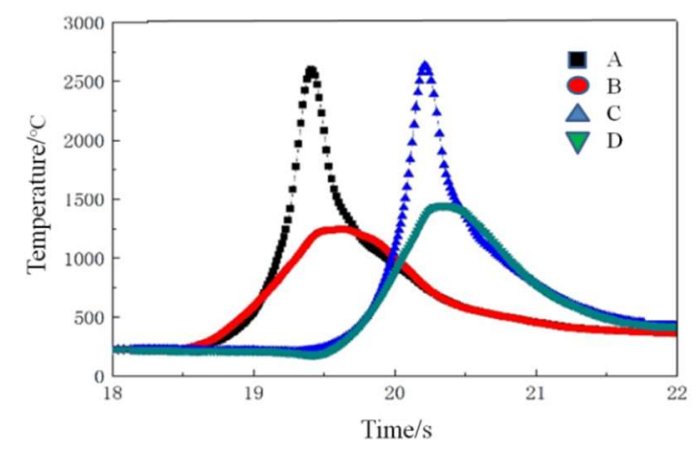

(c)

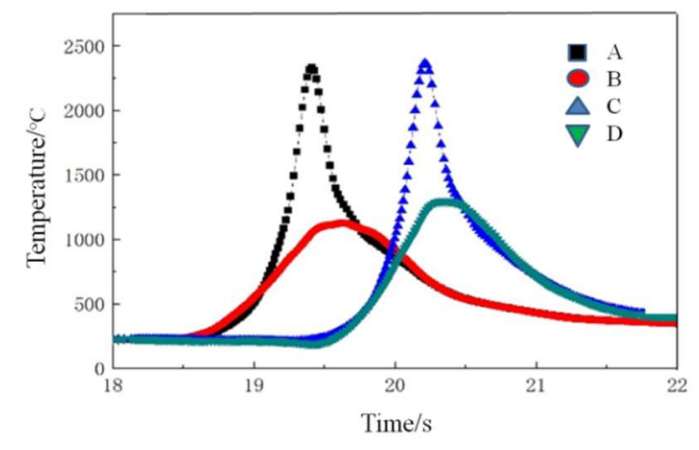

(b)

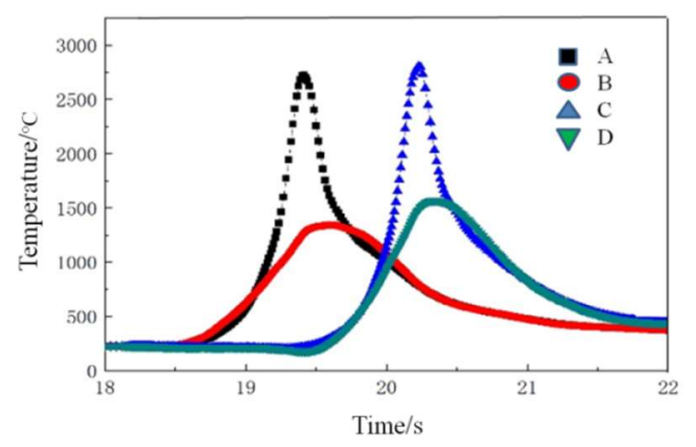

(d)

Figure 7 Curve of different currents with laser 200w (a) $4 \mathrm{~A}$; b) $16 \mathrm{~A}$;(c) $25 \mathrm{~A}$;(d) $32 \mathrm{~A}$

As shown in Figure 8a, b and c, the temperature at point B is lower than $1200^{\circ} \mathrm{C}$, which cannot form a molten pool with the substrate and thus cannot be well fused with the substrate. When the current is increased to $32 \mathrm{~A}$, the temperature at point $\mathrm{B}$ is higher than $1200^{\circ} \mathrm{C}$, which can form a molten pool with the substrate and fuse together well. Therefore, when the laser power is $150 \mathrm{w}$ and the current is $32 \mathrm{~A}$, it is a better process parameter.

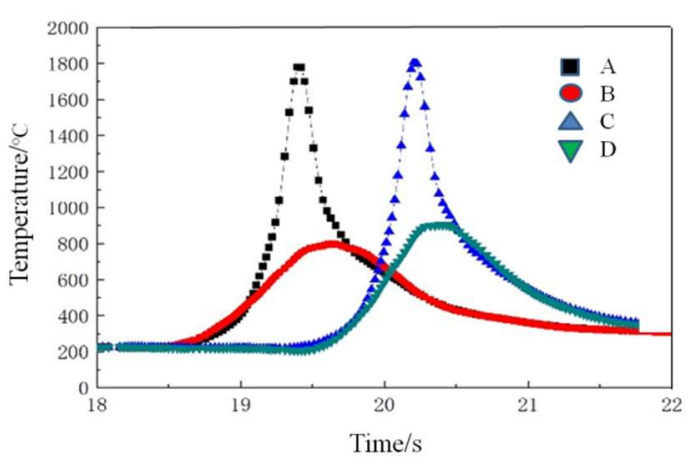

(a)

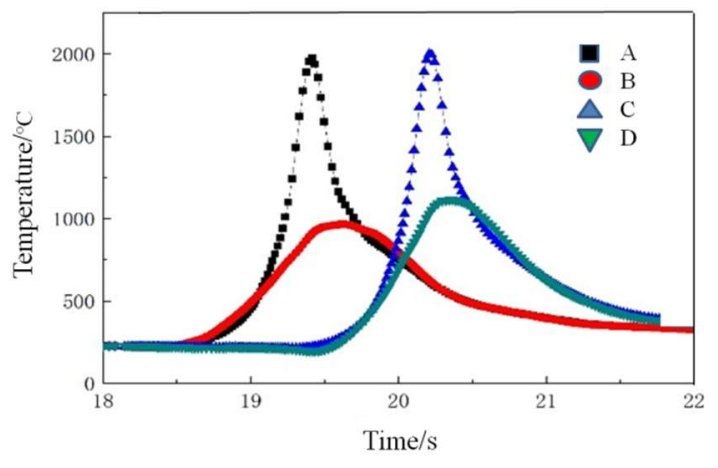

(b) 


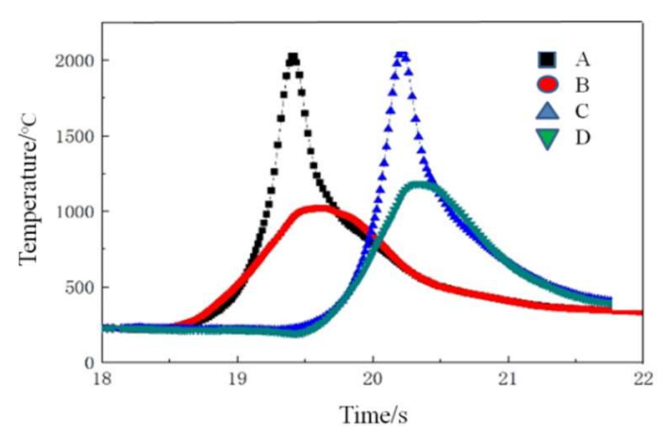

(c)

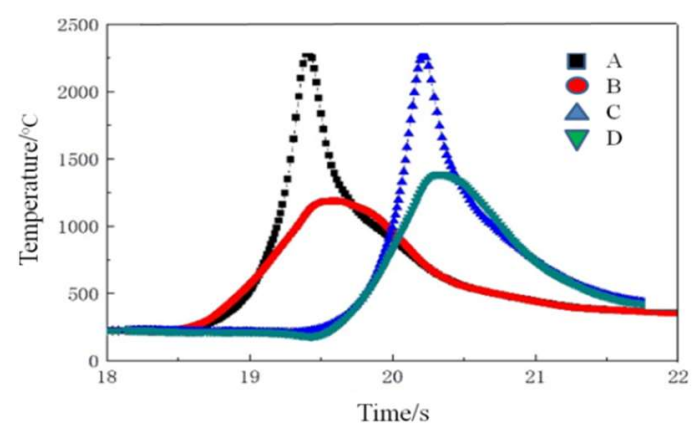

(d)

Figure8 Curve of different currents with laser 150w (a) 4A; b) $16 \mathrm{~A}$; (c) $25 \mathrm{~A}$;(d) $32 \mathrm{~A}$

according to the single-layer additive manufacturing obtained above, the optimization of the process parameters

(as shown in Table 3) are selected, that is, when the scanning speed is $5 \mathrm{~mm} / \mathrm{s}$, substrate temperature is $250^{\circ} \mathrm{C}$, wire feeding speed is $540 \mathrm{~mm} / \mathrm{min}$, voltage is $10 \mathrm{~V}$, the laser power is $250 \mathrm{w}, 200 \mathrm{w}, 150 \mathrm{w}$, the current is $16 \mathrm{~A}, 25 \mathrm{~A}$ and $32 \mathrm{~A}$ respectively, On the basis of single-layer parts, the process parameters are used for multi-layer parts, as shown in table 3.

Table 3 Optimal process parameters

\begin{tabular}{ll}
\hline Parameters & Numerical value \\
\hline Laser power $/ W$ & $150,200,250$ \\
Current $/ A$ & $32,25,16$ \\
Scanning speed $/ \mathrm{mm}^{-1}{ }^{-1}$ & 5 \\
Substrate temperature ${ }^{\circ} \mathrm{C}$ & 250 \\
Wire feeding speed $/ \mathrm{mm}^{\mathrm{m}} \mathrm{min}^{-1}$ & 540 \\
Voltage $/ V$ & 10 \\
\hline
\end{tabular}

\subsubsection{Morphology characterization}

When the laser power is $250 \mathrm{w}$ and the current is $4 \mathrm{~A}$, the wire cannot be well bonded with the substrate, which can be seen from table 4(1). The current from 4A to 16A gradually increases, but only the morphology of forming layer in Table 4 (2) is best, and the wire can be firmly bonded to the substrate. The thickness of table 4 (3) is not uniform, and dot morphology appears in table 4 (4). 
Table 4 Morphology of 250w laser with different current

\begin{tabular}{ccc}
\hline number & laser power(W) & current(A) \\
\hline 1 & 250 & 4 \\
2 & 250 & 16 \\
3 & 250 & 25 \\
4 & 250 & 32 \\
\hline
\end{tabular}

When the laser power is $200 \mathrm{w}$ and the current is 4, 16, 25 and 32 A respectively, current increases successively as shown in Table 5 (1)-(4), in which Table 5 (3) is the best, the thickness in Table 5(1) and (2) is uneven, Table 5 (4) are formed due to the high current point.

Table 5 Morphology of 200w laser with different current

\begin{tabular}{|c|c|c|c|}
\hline number & forming layer & laser power(W) & current $(\mathrm{A})$ \\
\hline 1 & 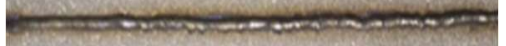 & 200 & 4 \\
\hline 2 & 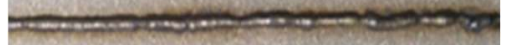 & 200 & 16 \\
\hline 3 & 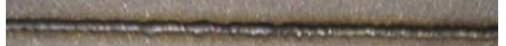 & 200 & 25 \\
\hline 4 & 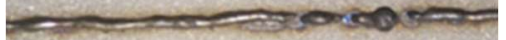 & 200 & 32 \\
\hline
\end{tabular}

When the laser power is $150 \mathrm{w}$ and the current is 4, 16, 25 and $32 \mathrm{~A}$ respectively. The morphology of the layers are shown in Table 6. It can be seen that the wire cannot be completely melted and the wire is broken, as shown in Table 6 (1), (2) and (3). But when the current is increased to 30A, the wire is firmly bonded to the substrate and can be combined with the substrate well, as shown in Table 6 (4). This is because during the forming process, the temperature at the bottom of the forming layer is relatively low. Therefore, when the laser power is $150 \mathrm{w}$ and the current is $32 \mathrm{~A}$, it is a better process parameter.

Table 6 Morphology of $150 \mathrm{~W}$ laser with different current

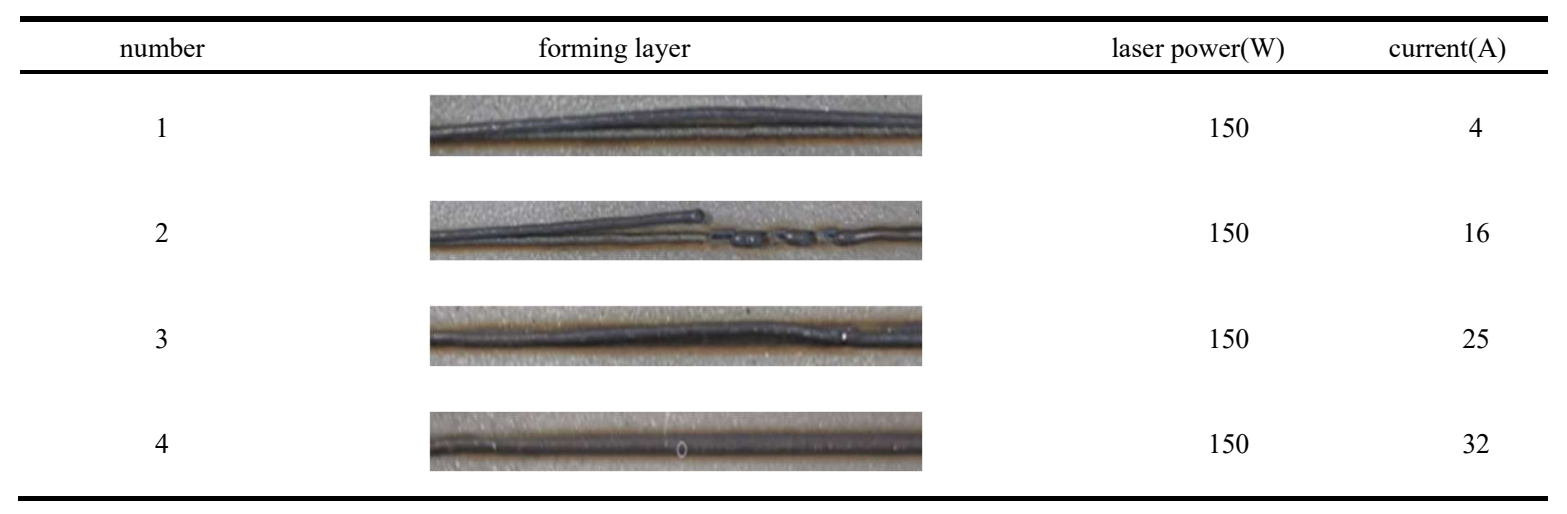


according to the single-layer additive manufacturing obtained above, the optimization of the process parameters (as shown in Table 7) are selected, that is, when the scanning speed is $5 \mathrm{~mm} / \mathrm{s}$, substrate temperature is $250^{\circ} \mathrm{C}$, wire feeding speed is $540 \mathrm{~mm} / \mathrm{min}$, voltage is $10 \mathrm{~V}$, the laser power is $250 \mathrm{w}, 200 \mathrm{w}, 150 \mathrm{w}$, the current is $16 \mathrm{~A}, 25 \mathrm{~A}$ and $32 \mathrm{~A}$ respectively, On the basis of single-layer parts, the process parameters are used for multi-layer parts, as shown in table 8.

Table 7 Optimal process parameters

\begin{tabular}{ll}
\hline Parameters & Numerical value \\
\hline Laser power $/ W$ & $150,200,250$ \\
Current $/ A$ & $32,25,16$ \\
Scanning speed $/ \mathrm{mm}^{-1}{ }^{-1}$ & 5 \\
Substrate temperature ${ }^{\circ} \mathrm{C}$ & 250 \\
Wire feeding speed $/ \mathrm{mm}^{\mathrm{m}} \mathrm{min}^{-1}$ & 540 \\
Voltage $/ V$ & 10 \\
\hline
\end{tabular}

In the case of other parameters unchanged, when the laser power is $250 \mathrm{w}, 200 \mathrm{w}, 150 \mathrm{w}$, the current is $16 \mathrm{~A}$, and $25 \mathrm{~A}$ and $32 \mathrm{~A}$ respectively, the good performance of the cladding layer can be obtained. That is the optimal resistance heat, which can make full use of resistance heat and reduce the dependence on laser without causing the welding wire to fuse outside the molten pool. So that it can gradually reduce the laser power and apply current to find the process parameters of composite heating.

Table 8 Layer morphology of $150 \mathrm{~W}$ laser with different current values

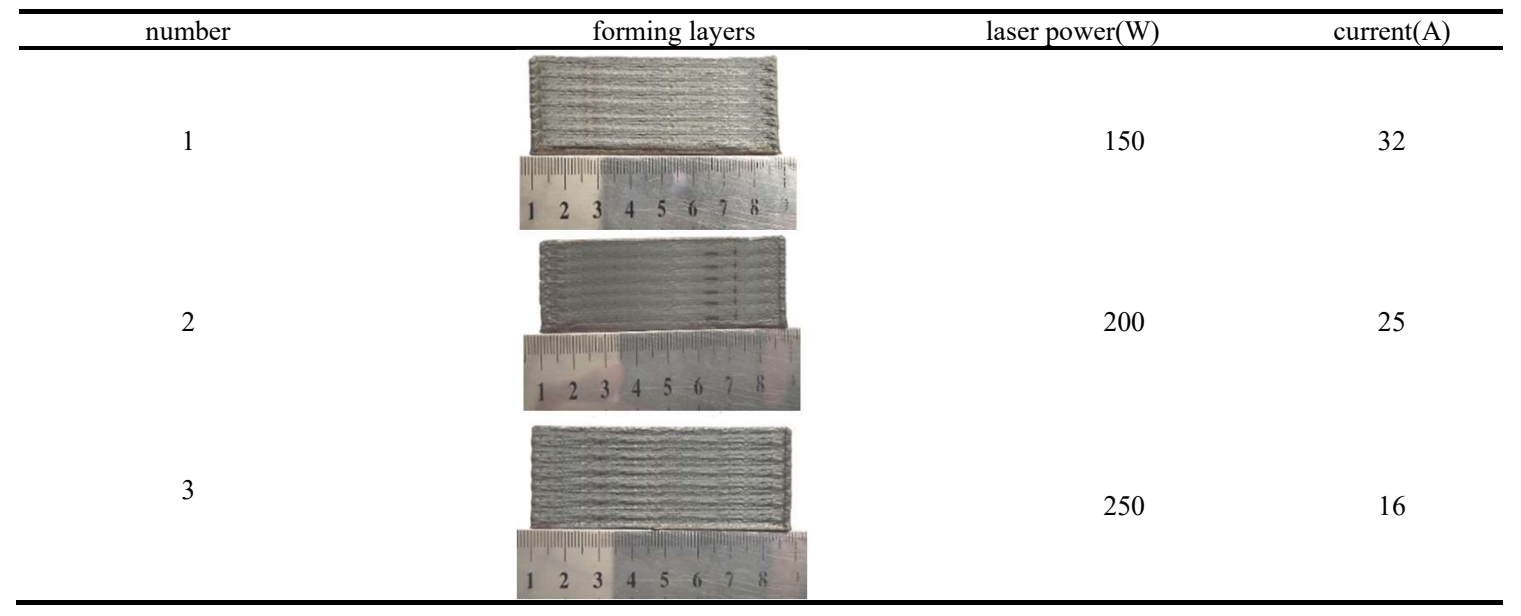

\subsection{Density}

The density of the part is an important index to measure the internal quality of the metal part. Density strengths along the horizontal and vertical directions of the samples built by three different processes are presented in Table 7. Each reported value is an averaged value of three test results. After degreasing and cleaning, the mass of the samples 
in air and the water have used a balance to weigh respectively, and then according to the formula (5) obtain the density of the sample.

$$
\rho=\frac{m_{1}}{m_{1}-m_{2}} \rho_{2}
$$

Where, $m_{l}$ is the mass of the sample to be tested measured in air; $m_{2}$ is the mass of the sample to be tested fully immersed in water; $\rho$ is the density of the tested sample and $\rho_{2}$ is the density of water.

When the laser power is $150 \mathrm{w}$ and the current is $32 \mathrm{~A}$, the density is $97.7 \%$. When the laser power is $200 \mathrm{w}$ and the current is $25 \mathrm{~A}$, the density is $97.8 \%$. And when the laser power is $250 \mathrm{w}$ and the current is $16 \mathrm{~A}$, the density is $98.1 \%$. It can be seen that the compactness of the part is very high, and the layers can be fully fused under the better process parameters to realize the metallurgical bonding between the overlapping layer materials.

\subsection{Tensile performance}

Tensile strengths along the horizontal and vertical directions of the samples (shown in Table 8) built by three different processes are presented. Each reported value is an averaged value of three test results. The horizontal and vertical tensile strengths are $690.07 \mathrm{MPa}$ and $688.50 \mathrm{MPa}$ respectively when the laser power is $150 \mathrm{w}$ and the current is $32 \mathrm{~A}$. It indicates that the tensile strength has little anisotropy under this deposition process. The horizontal and vertical tensile strengths are 796.3MPa and 795.2 MPa respectively when the laser power is $200 \mathrm{w}$ and the current is $25 \mathrm{~A}$. Larger difference between the two directions is found when the laser power is $250 \mathrm{w}$ and the current is $16 \mathrm{~A}$, whose horizontal and vertical tensile strength are 866.67 $\mathrm{MPa}$ and 860.23 $\mathrm{MPa}$, respectively.

It also can be seen from Table 9 that the strength of the 316L stainless steel specimens prepared under the three different processes is higher than the standards of castings and forgings, and the tensile strength of the specimens' increases with the increase of laser power

Table 9 Comparison of tensile mechanical properties of different specimens

\begin{tabular}{ccc}
\hline & \multicolumn{2}{c}{ Tensile stress(MPa) } \\
\cline { 2 - 3 } Number & horizontal directions & vertical directions \\
\hline $1(150 \mathrm{w}-32 \mathrm{~A})$ & 690.07 & 688.50 \\
$2(200 \mathrm{w}-25 \mathrm{~A})$ & 796.30 & 795.20 \\
$3(250 \mathrm{w}-16 \mathrm{~A})$ & 866.67 & 860.23 \\
Casting $(\mathrm{CF}-3 \mathrm{M})$ & & 552 \\
\hline Heat-treated and annealed bar & & \\
\hline
\end{tabular}



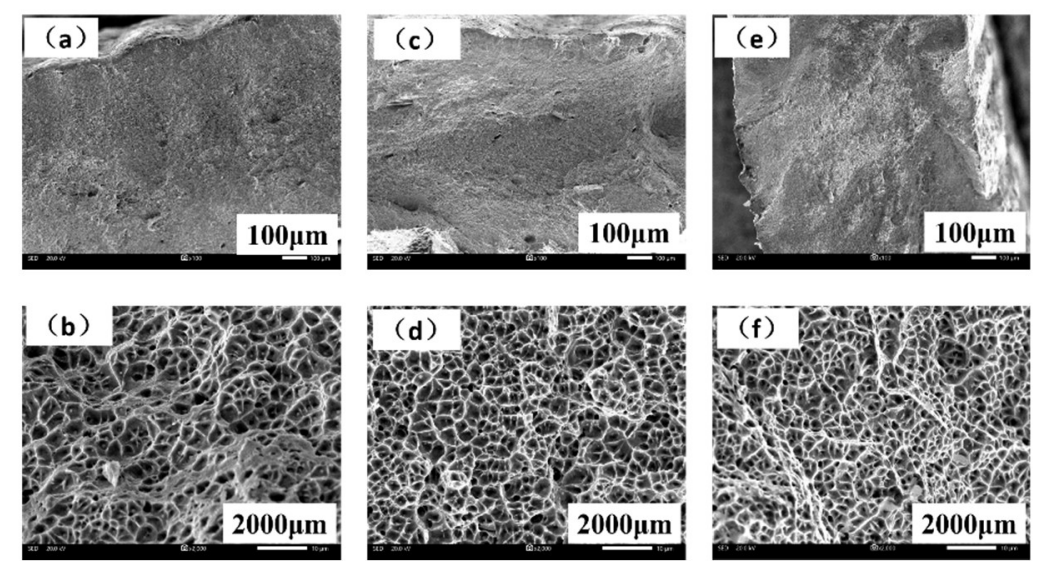

Figure 9 Fracture morphology of tensile specimens

Figure 9 is a macroscopic view of the fracture. It can be seen from the morphology of the fracture that the test fracture has no defects such as unfusion, which is consistent with the observation results of the microstructure of the sample. Figure 9 (a), (c) and (e) show that the fractures have typical dimple features, and the dimples are deeper. Figure 9 (b), (d) and (f) has obvious edges at the edges of the break deformation, which shows that the sample has better plasticity.

\subsection{Industrial CT test}

The parts shown in table 10 were tested by industrial CT. When the laser power is $150 \mathrm{w}$ and the current is $32 \mathrm{~A}$, the defect volume ratio is $4 \%$. When the laser power is $200 \mathrm{w}$ and the current is $25 \mathrm{~A}$, the defect volume ratio is $2.4 \%$. And when the laser power is $250 \mathrm{w}$ and the current is $16 \mathrm{~A}$, the defect volume ratio is $1.7 \%$. (As shown in table 10). Defects basically appear on both ends of the part, at the start and stop positions of printing. The main reason is that at the beginning of printing, the wire has been preheated to a certain temperature and melted instantly under the high energy of the laser. The air path is opened at the same time, and part of the oxygen is drawn in, causing the parts to have pores. When printing stops, the laser and the gas circuit are closed at the same time. At this time, the metal has not completely solidified, and there will be oxygen inclusions to form pores. 
Table 10 specimens tested by industrial CT

\begin{tabular}{|c|c|c|}
\hline Number & Elastic Modulus (MPa) & defect volume ratio \\
\hline $1(150 w-32 A)$ & & $4 \%$ \\
\hline $2(200 w-25 A)$ & & $2.4 \%$ \\
\hline $3(250 w-16 A)$ & & $1.7 \%$ \\
\hline
\end{tabular}

\section{Conclusions}

(1) When the laser power is $250 \mathrm{w}, 200 \mathrm{w}, 150 \mathrm{w}$, and the current is $16 \mathrm{~A}, 25 \mathrm{~A}, 32 \mathrm{~A}$ respectively, the results of meet the requirements can be obtained. The results of multi-layer additive manufacturing show that each printing layer will affect the subsequent printing, which is equivalent to the effect of preheating. Each layer printed up will also affect the previous additive manufacturing layer, but this effect will become smaller and smaller, so the wave peaks appear at regular intervals but show a gradual decline. .

(2) The correctness of the simulation results was verified through experiments. Through process optimization, the best process parameters were determined to be 250w, 16A; 200w, 25A; 150w, 32A; and multi-layer experiments were carried out with the best parameters of $250 \mathrm{w}, 16 \mathrm{~A}$.

Author Contributions: S.L. performed experiments and wrote this manuscript. C.X. and B.L. designed the research, helped analyze the experimental data, and gave some constructive suggestions. K.M. and L.Y. participated in the discussion about the results and helped the experiments. C.X.helped the experimental design and Language Editing. Funding: The work was financially supported by State Key Laboratory for Manufacturing Systems Engineering in china [grant number sklms2021016].

Acknowledgments: This work is supported by the National Innovation Institute of Additive Manufacturing, China. The authors additionally acknowledge the work of Jiale Li, Wenxuan Yang, Baofeng Wen and Zhezhi Lai for the initial work on performing the fundamental experiments.

Conflicts of Interest: The authors declare no conflict of interest.

\section{REFERENCES}

[1] Fang, X.; Zhang, L.; Li, H.; Li, C.; Huang, K.; Lu, B. Microstructure evolution and mechanical behavior of 2219 aluminium alloys additively fabricated by the cold metal transfer process. Materials 2018, 11, 812.[CrossRef]

[2]Wang, X.;Shen, F.; Overview of additive manufacturing technology [J] Jiangxi Chemical Industry, Issue 3, 2019: 242-243. [CrossRef] 
[3] Williams, S.W.; Martina, F.; Addison, A.C.; Ding, J.; Pardal, G.; Colegrove, P. Wire + arc additive manufacturing. Mater. Sci. Technol. 2016, 32, 641-647. [CrossRef]

[4] Colegrove, P.A.; Coules, H.E.; Fairman, J.; Martina, F.; Kashoob, T.; Mamash, H.; Cozzolino, L.D. Microstructure and residual stress improvement in wire and arc additively manufactured parts through high-pressure rolling. J. Mater. Process. Technol. 2013, 213, $1782-1791$. [CrossRef]

[5] Prashanth, K.G.; Shahabi, H.S.; Attar, H.; Srivastava, V.C.; Ellendt, N.; Uhlenwinkel, V.; Eckert, J.; Scudino, S.Production of high strength A185Nd8Ni5Co2 alloy by selective laser melting. Addit. Manuf. 2015 , 6, 1-5.[CrossRef]

[6] Kaibyshev, R.; Musin, F.; Lesuer, D.R.; Nieh, T.G. Superplastic behavior of an Al-Mg alloy at elevated temperatures. J. Mater. Sci. Eng. A 2003, 342, 169-177. [CrossRef]

[7] Zhang, C.; Li, Y.; Gao, M.; Zeng, X. Wire arc additive manufacturing of Al-6Mg alloy using variable polarity cold metal transfer arc as power source. Mater. Sci. Eng. A 2018, 711, 415-423. [CrossRef]

[8]Su Yanwen. Research on surface additive manufacturing process and performance of semiconductor laser-TIG arc composite heat source[D]. Lanzhou University of Technology, 2016. [CrossRef]

[9] Wen Peng. Control of wire transfer behaviors in hot wire laser welding [J]. Int J Adv Manuf Technol (2016) 83:2091-2100. [CrossRef]

[10] Peng Wen, Zhenhua Feng, Shiqing Zheng.Formation quality optimization of laser hot wire cladding for repairing martensite precipitation hardening stainless steel[J]. Optics \& Laser Technology 65 (2015) 180-188. [CrossRef]

[11] Dieter Tyralla a, Thomas Seefeld. Temperature field based closed-loop control of laser hot wire cladding for low dilution[J]. 11th CIRP Conference on Photonic Technologies [LANE 2020] on September 7-10, 2020. [CrossRef]

[12]Yuan Ming, Huo Hongjie, Yan Donghuang. Research on hydration heat of box girder of high-pier and large-span continuous rigid frame bridge[J]. China and Foreign Highway, 2011, 31(03): 138-142. [CrossRef]

[13]Zheng Zhentai, Lu Huimin, Zhang Kai, Shan Ping, Hu Shengsun. Fusion welding heat source model and its development trend[J]. Welding, 2008(04): 3-6+68. [CrossRef]

[14] Chaijaruwanich, A.; Lee, P.D.; Dashwood, R.J.; Youssef, Y.M.; Nagaumi, H. Evolution of pore morphology and distribution during the homogenization of direct chill cast Al-Mg alloys. Acta Mater. 2007 , 55, 285-293.[CrossRef]

[15] Huang, K.; Zhao, Q.; Li, Y.; Marthinsen, K. Two-stage annealing of a cold-rolled Al-Mn-Fe-Si alloy with different microchemistry states. J. Mater. Process. Technol. 2015, 221, 87-99. [CrossRef]

[16] Huang, K.; Marthinsen, K.; Zhao, Q.; Logé, R.E. The double-edge effect of second-phase particles on the recrystallization behaviour and associated mechanical properties of metallic materials. Prog. Mater. Sci. 2017 .[CrossRef]

[17] Ding, D.; Pan, Z.; Cuiuri, D.; Li, H. Wire-feed additive manufacturing of metal components: Technologies, developments and future interests. Int. J. Adv. Manuf. Technol. 2015, 81, 465-481. [CrossRef]

[18] Colegrove, P.A.; Coules, H.E.; Fairman, J.; Martina, F.; Kashoob, T.; Mamash, H.; Cozzolino, L.D. Microstructure and residual stress improvement in wire and arc additively manufactured parts through high-pressure rolling. J. Mater. Process. Technol. 2013, 213, 1782-1791. [CrossRef]

(C) 2021 by the authors. Licensee MDPI, Basel, Switzerland. This article is an open access article distributed under the terms and conditions of the Creative Commons Attribution (CC BY) license (http://creativecommons.org/licenses/by/4.0/). 